\title{
Use of Styrene Butadiene Rubber (SBR) Polymer in Cement Concrete
}

\author{
Asaf Nawaz Khan ${ }^{1}$, Naraindas Bheel2,*, Masroor Ahmed ${ }^{3}$, \\ Rameez Ali Abbasi ${ }^{4}$ and Samiullah Sohu ${ }^{5}$ \\ ${ }^{1}$ Civil Engg., Mehran UET Jamshoro, Sindh, Pakistan \\ ${ }^{2}$ Civil Engineering Department, H.C.S.T Hyderabad, Sindh, Pakistan \\ ${ }^{3}$ Civil Engg., SUS\&IT Peshawar, Pakistan \\ ${ }^{4}$ Civil Engineering Department, Indus University Karachi, Sindh, Pakistan \\ ${ }^{5}$ Civil Engineering Department, QUEST Campus Larkana, Sindh, Pakistan
}

\section{Article Type: Article \\ Article Citation: Asaf Nawaz Khan, Naraindas Bheel, Masroor Ahmed, Rameez Ali Abbasi, Samiullah Sohu. Use of styrene butadiene rubber (SBR) polymer in cement concrete. Indian Journal of Science and Technology. 2020; 13(05), 606-616. D0I: 10.17485/ ijst/2020/v013i05/148936}

Received date: November 16, 2019

Accepted date: January 14, 2020

*Author for correspondence: Naraindas Bheel Vudasinarain@ gmail.com $\bigcirc$ Civil Engineering Department, H.C.S.T Hyderabad, Sindh, Pakistan

\begin{abstract}
Objectives: This research work was adopted to have the maximum strength of concrete mixed with styrene-butadiene rubber (SBR) and to know the effect of SBR on the fresh and hardened concrete. Methods/statistical analysis: The concrete samples were prepared to achieve targeted strength of $3000 \mathrm{lb} / \mathrm{in}^{2}$. In this experimental work, the mixture of concrete was prepared by adding $0 \%, 5 \%$, $10 \%, 15 \%$, and $20 \%$ of SBR polymer-cement ratio to check the properties of fresh concrete (slump test and compaction factor test), while rebound hammer test, ultrasonic pulse velocity test (UPV), compressive strength test, and tensile strength test were observed at 7th, 14th, and 28th days, respectively. Findings: Resultantly, the compressive strength and indirect tensile strength boosted by $16 \%$ and $13 \%$ blended with $15 \%$ of SBR polymer in concrete as compared to control concrete after 28th days, respectively. The workability of fresh concrete plummeted with a rise in the amount of SBR polymer in concrete. Application/improvements: Both the quality and high strength of concrete is improved by adding $15 \%$ of SBR in concrete.
\end{abstract}

Keywords: Styrene-Butadiene Rubber (SBR), Additional Material, Increases Strength of Concrete.

\section{Introduction}

Concrete consists of a blend of cement mixture, aggregates, water and, not so usual, admixtures that add up to its strength and improve its certain physical and mechanical properties [1-2]. It is plausible to get various kinds of concrete based on its use by altering the ingredients and addition of some natural and chemical admixtures [3]. With 
comparison to the other substances used as construction materials, concrete has got to be a commonplace and widespread, frequently preferred across the globe due to its strength, durability, availability and being economical, and less consumption of energy for the production, regardless of the environmental hazardous and degradation [4-5]. Encompassing the service life, and under the sustainable environmental conditions, the strength, durability, and form are retained throughout this tenure. Since concrete deteriorates with the passage of time, the materials blended in it must be protected with appropriate proportion together with the addition of some preserving admixtures. Flow ability, strength as well durability makes the crucial three functions of concrete. Preparing the concrete to conform to the aforementioned properties, and being environmental friendly, suitable design method and quality control should be followed with the correct alteration of ingredients along with the use of admixtures at all the stages of production and, later, in mixing proportion [6-7]. With the advent of research and development in science and technology, concrete industry too has flourished with the introduction of new and novel innovations of concrete, hence concrete made with regard to specific demands and properties is famously known to special concrete. Special concrete is one that is manufactured in accordance with its purpose to meet different expectations. Basically heavy weight concrete, light weight concrete, liquidated concrete, and insulating-concrete are some of the examples of special concrete [8]. In the 1950s, synthetic-polymers were used in Portland cement mortar and concrete as polyvinyl acetate and polyacrylate. Unpredictably, afterwards, the amount of synthetic polymer latex in the cement modified with polymer has mushroomed up and has got greater precedence over the natural rubberlatex [9]. Synthetic polymers used as styrene-butadiene rubber (SBR) latex in cement technology have been recognized in many fronts [10-12]. The use of polymer used as regulator in the newly constructed structures puts forward new horizons of development in the microstructures and the strength of cement mortar as well as concrete [13-14]. Workability, strength, mechanical parameters of aggregates and cement mix are affected to a larger extent by the use of polymers, hence polymers impart a pivotal effect on the said. Styrene-butadiene polymers, undoubtedly, in the concrete technology, are, as a rule, the most generally used polymer materials [15].

SBR is a wide distribution polymer containing of butadiene, styrene, and water, which can be successfully combined with various materials [16-17]. Since vinyl pyridine latex is poorly immersed in fabrics, its main engineering application is the immersion of tires in the textile industry [18]. In civil engineering field, SBR is utilized as a substitute of cement to boost the hardened properties of concrete [19]. The research outcome was observed that the effect of addition SBR on the characteristics strength concrete. SBR is the most widely used cement mortar modifier and shows its chemical composition. High adhesion is observed in the resulting polymer film and cement hydrate. Compared to ordinary concrete, this influence causes less deformation and improves the crushing and flexural strength of concrete [20]. SBR latex has got widespread use in modified solutions to a colossal extent. The findings have shown that solutions modified with SBR have improved mechanical parameters i.e. improved impermeability and greater resistance to frost action [21]. 
In Ref. [22], Karahan and Atiş studied the role of fly ash, which is used as a mineral additive rather than cement (on Achieve $40 \%$ of the performance of HSC in cement mixtures). The standard-size cube specimens $(6 " \times 6 " \times 6$ ") were prepared with 0.35 water/ binder ratio. The additional material such as plasticizer is used in concrete to enhance slump value, and the concrete crushing strength is $78 \mathrm{MPa}$ were achieved after 28 days. It was, later on, fathomed out that the incorporation of fly-ash, a byproduct from plants is significantly crucial with regard to the economy as well as to the environmental merits.

In Ref. [23], Rossignolo and Agnesini studied the characteristics strength of lightweight polymer-modified concrete by the addition of SBR to Brazilian lightweight concrete to analyze crushing strength. The research outcomes was recorded that the crushing strength achieved by 39.7-51.9 MPa after 7 days and they determined that thin prefabricated elements could be made by modifying SBR for the Brazilian lightweight aggregate can produce materials.

In Ref. [24], Atiyah et al. analyzed the crushing strength of concrete blended with combination of SBR. In this experimental work, the slump value of SBR concrete was improved by using plasticizer in concrete. The concrete samples were prepared with the addition of $0 \%-15 \%$ SBR with interval of $5 \%$. Studies have shown that if the proportion of polymer increases, the compressive strength decreased by $17.8 \%$ at $5 \%$ SBR, Split tensile and flexural strength were improved by $15.6 \%$ and $15 \%$ at $10 \%$ SBR after 28 days, respectively.

In Ref. [25-26], authors studied the characteristics strength of polymer-modified concrete by the addition of $0 \%-20 \%$ SBR to analyze crushing strength. The research outcomes was recorded that the crushing strength achieved maximum at 15\% of SBR after 28 days.

In Ref. [27], Shafieyzadeh analyzed the crushing strength of concrete blended with the combination of SBR and silica powder. In this experimental work, the slump value of SBR concrete was improved by using plasticizer in concrete. The concrete samples were prepared with addition of $0 \%-15 \%$ SBR and $0 \%-10 \%$ silica powder, respectively. Studies have shown that if the proportion of polymer increases, the compressive strength decreased.

The use of SBR as a simulated polymer is necessary to reduce the ratio of water to cement in the mixture, thereby increasing strength with a significant reduction in permeability. The aim of this work was to investigate the effect of SBR polymers on the properties of fresh, physical, and hardened concrete.

\section{Materials}

\subsection{Cement}

Ordinary Portland cement (OPC) was used as a binder under the brand name "Askari Cement" and it was collected from Peshawar, Pakistan. The preliminary tests of the cement were conducted and found as: the normal consistency of $32 \%$, initial and final setting time is $45 \mathrm{~min}$ and $130 \mathrm{~min}$, respectively. 


\subsection{Fine and Coarse Aggregates}

The Nizampoor Sand was used as fine aggregates of Zone-II that collected from Peshawar, Pakistan. The Nizampoor Sand was passed through a $4.75 \mathrm{~mm}$ sieve for removing excess material and Margala Crushed stone was used as coarse aggregates and collected from local market Peshawar, Pakistan. The coarse aggregates used in this work having a size of $20 \mathrm{~mm}$. The various tests conducted in the laboratory to ensure the quality of the aggregates, as shown in Table 1 .

TABLE 1. Physical properties of fine \& coarse aggregates

\begin{tabular}{llcc}
\hline S. no & Properties & Fine aggregates & Coarse aggregates \\
\hline 01 & Fineness modulus & 2.20 & - \\
02 & Water absorption & $1.54 \%$ & $0.64 \%$ \\
03 & Specific gravity & 2.40 & 2.75 \\
04 & Moisture content & $3.14 \%$ & $0.15 \%$ \\
05 & Bulk density & $115 \mathrm{lb} / \mathrm{ft}^{3}$ & $92 \mathrm{lb} / \mathrm{ft}^{3}$ \\
\hline
\end{tabular}

\subsection{Styrene-Butadiene Rubber}

It was made through suspension polymerization of styrene and butadiene monomers. Resulting SBR has average molecular weight ranges from 250,000 to 800,000. It was taken from SILICA Company Lahore, Pakistan. Such polymerization is found an effective for SBR performance [28]. SBR was using various proportions by the weight of cement in concrete.

\subsection{Water}

The clean and drinkable water was used in experimental work.

\section{Research Methodology}

This research work was adopted by using several proportions like $0 \%, 5 \%, 10 \%, 15 \%$, and $20 \%$ of SBR by the weight of cement in concrete in order to find the fresh and hardened concrete. A total of 90 cylinder concrete samples were made and cured after 7, 14, and 28 days to achieve targeted strength of 3000 psi. In order to obtain the required strength results, many mixing trials were made with variable cement (binder), fine and coarse aggregates, and water. In this research work, the number of cylinder specimens was used to determine the characteristics strength such as ultrasonic pulse velocity test (UPV), compressive strength test, rebound hammer test, and tensile strength test were performed after 7 th, 14th, and 28th days, respectively. Moreover, ACI mix design method was considered under this experimental work to find the proportions of concrete ingredients. This investigation effort was done in the concrete and structural Engineering laboratory, Department of Civil Engineering, Sarhad US\&IT Peshawar, Pakistan. Different mixes were prepared with the inclusion of SBR by the weight of cement as summarized below in Table 2. 
TABLE 2. Details of all mixes

\begin{tabular}{lcccccc}
\hline S. no & Mix. ID & $\begin{array}{c}\text { Cement } \\
\text { (\%) }\end{array}$ & $\begin{array}{c}\text { Styrene- } \\
\text { butadiene } \\
\text { rubber (\%) }\end{array}$ & $\begin{array}{c}\text { Fine } \\
\text { aggregates } \\
\text { (\%) }\end{array}$ & $\begin{array}{c}\text { Coarse } \\
\text { aggregates } \\
\text { (\%) }\end{array}$ & $\begin{array}{c}\text { Water- } \\
\text { cement } \\
\text { ratio (\%) }\end{array}$ \\
\hline 1 & $1: 2.86: 3.51$ & 100 & 0 & 100 & 100 & 0.59 \\
2 & $1: 2.86: 3.51$ & 100 & 5 & 100 & 100 & 0.59 \\
3 & $1: 2.86: 3.51$ & 100 & 10 & 100 & 100 & 0.59 \\
4 & $1: 2.86: 3.51$ & 100 & 15 & 100 & 100 & 0.59 \\
5 & $1: 2.86: 3.51$ & 100 & 20 & 100 & 100 & 0.59 \\
\hline
\end{tabular}

\section{Results and Discussion}

\subsection{Slump Test}

It was used to analyze the workability in terms of slump reduction. The slump reduction was measured with the help of slump cone. The highest slump value was measured by 40 $\mathrm{mm}$ at $0 \%$ of SBR and the lowest slump value was recorded by $27 \mathrm{~mm}$ by using $20 \%$ of SBR as an admixture by the weight of cement in concrete, respectively. The experimental result was detected that the slump value reduces with rises in the amount of SBR polymer in concrete may be due to the less water available, as SBR required some water to coat its surface. Ultimately, lowers down due to lack of free available water which can impart workability as shown in Figure 1.

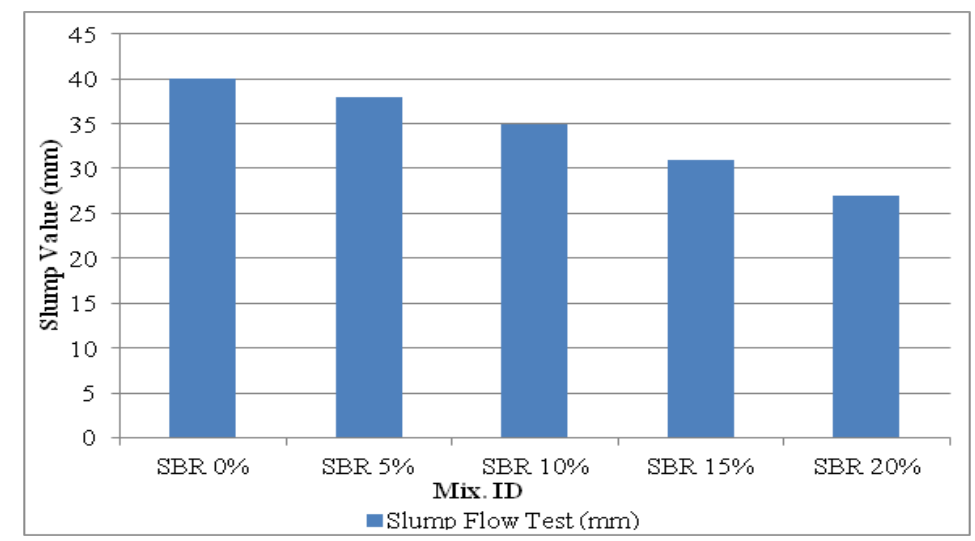

FIGURE 1. Workability of fresh concrete.

\subsection{Compacting Factor Test}

This test was used to find out the workability of fresh concrete on compaction factor appartus by following ASTM C597:2009 code procedure. The maximum amount of compaction factor was measured by 0.86 at $0 \%$ of SBR polymer and the minimum amount of compaction factor was recorded by 0.75 blended with $20 \%$ SBR polymer by the weight of cement in concrete, respectively. It was detected that the rate compaction factor drops with rises in the inclusion of SBR polymer in concrete as shown in Figure 2. 


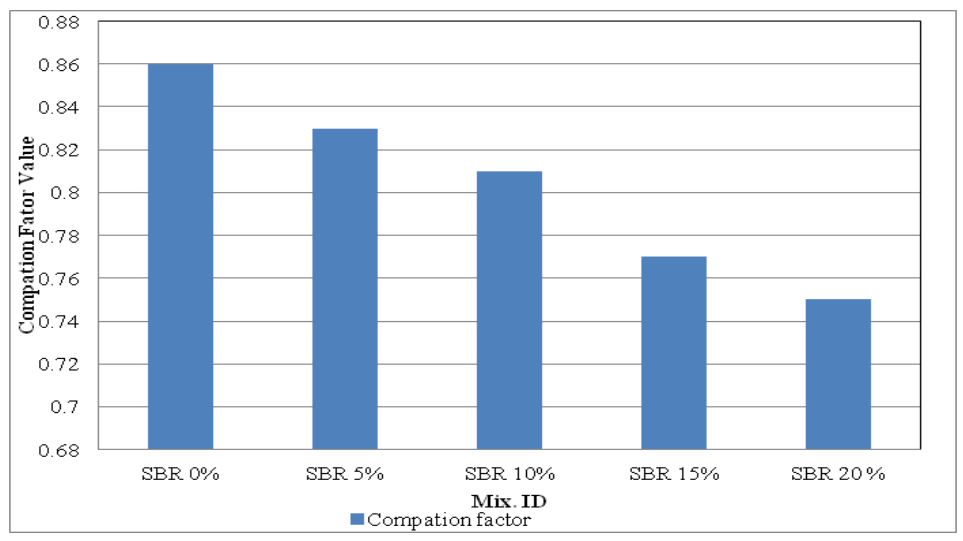

FIGURE 2. Workability measured by compaction factor.

\subsection{Non-Destructive Compressive Strengthby Rebound Hammer}

The compressive strength was determined by using non-destructive testing instrument, namely "Rebound Hammer" by following ASTM C805:2008 code. The crushing strength of concrete mixed with several proportions of SBR utilised as admixture were measured after 14th and 28th days. As shown in Figure 3, it is perceived that crushing strength get increased as SBR is increased up to $15 \%$ then after it starts decling. The crushing strength of SBR-based mixes is maximum than the control mix except $20 \%$ SBR-based mix. The superior compressive strength was obtained by 3260 psi and 3715 psi with the addition of $15 \%$ SBR and lowest compressive strength was measured by 2745 psi and 3175 psi blended with $20 \%$ of SBR in concrete after 14 th and 28 th days, respectively.

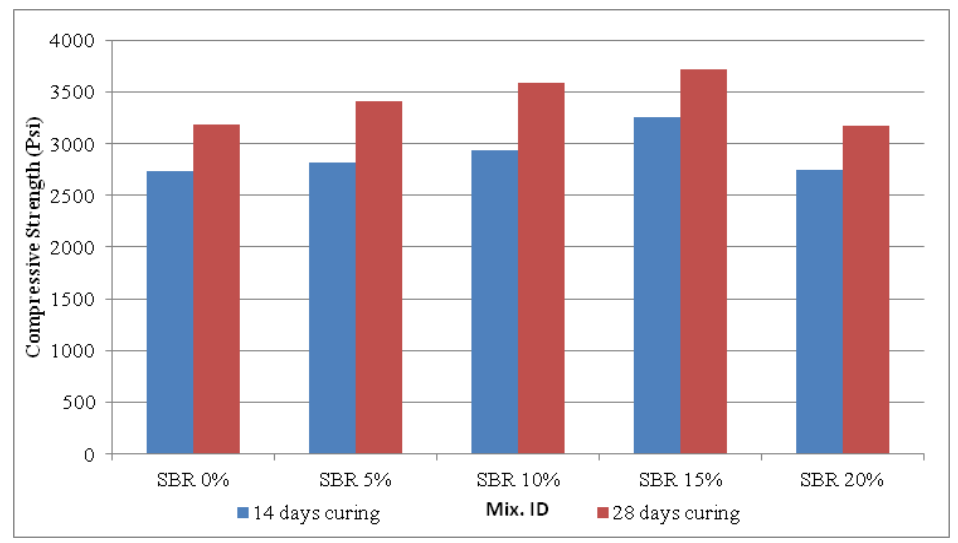

FIGURE 3. Compressive strength of concrete by rebound hammer.

\subsection{Destructive Compressive Strength by UTM Machine}

The cylindrical specimens were taken to analyze the crushing strength by "Universal Testing Machine" by obeying ASTM C39-05 a code.The crushing strength of concrete mixed with several proportions of SBR utilised as admixture were measured after 7 th, 14 th, and 28th days. As shown in Figure 4, it is perceived that compressive strength of 


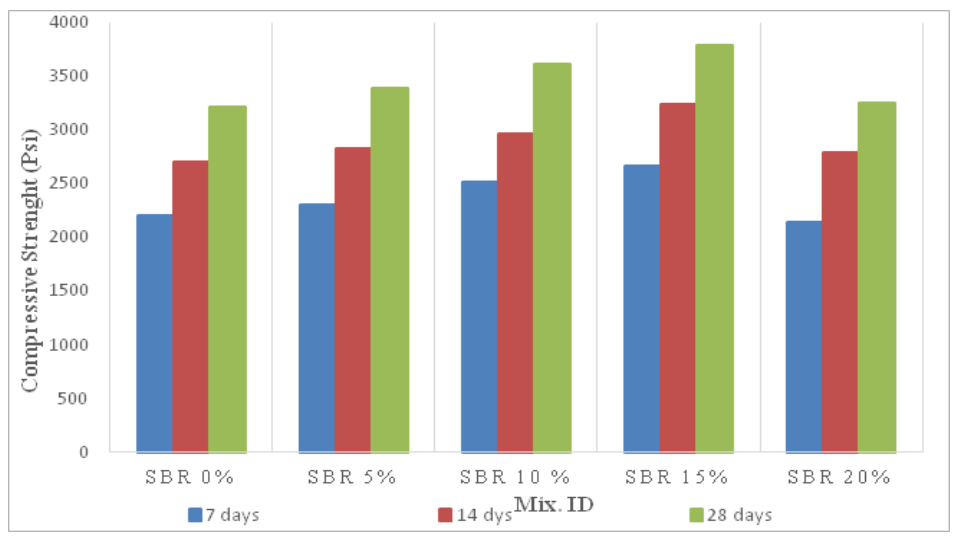

FIGURE 4. Compressive strength of concrete.

concrete improved with rise in the amount of SBR up to $15 \%$ beyond it starts reducing. This reduction in compressive strength may be due to decrease in density of concrete. The superior compressive strength was obtained by 2670 psi, 3240 psi, and 3795 psi with the addition of $15 \%$ SBR polymer and the lowest crushing strength was observed by 2145 psi, 2788 psi, and 3250 psi with the inclusion of $20 \%$ SBR polymer after 7 th, 14 th, and 28th days, respectively.

\subsection{SplittingTensile Strength}

The concrete cylinders $(6 \times 12$ in) were tested for indirect tensile strength on the UTM by following ASTM C 192-90 code procedure. Indirect tensile strength of control mix and mixes in which SBR used as admixture were determined after 7th, 14th, and 28th days. Figure 5 showed that indirect tensile strength of concrete increased with rise in the amount of SBR polymer up to $15 \%$ beyond it starts reducing. The highest value of indirect tensile strength was measured by 618.91 psi, 742.86 psi, and 803.91 psi with the addition of $15 \%$ SBR and the lowest value of split tensile strength was recorded by 503.22 psi, 670.93

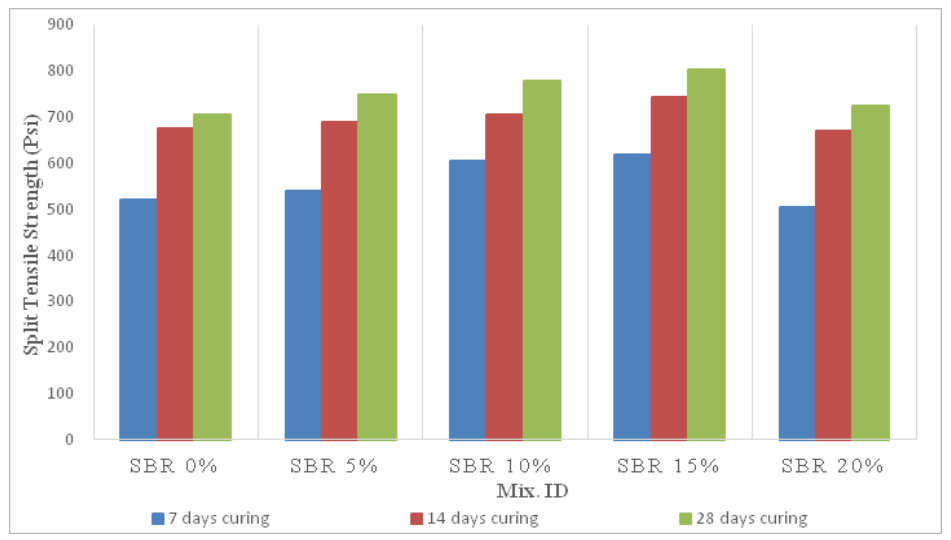

FIGURE 5. Spit tensile strength of concrete. 
psi, and 723.40 psi with the inclusion of $20 \%$ SBR polymer in cement concrete after 7 th, 14 th, and 28th days, respectively.

\subsection{Ultrasonic Pulse Velocity Test}

The test was done for testing the quality of concrete components (cracks, voids, and honeycombs) by following the test procedure ASTM C597: 2009, which is based on determining the propagation time of an ultrasonic pulse between two sensors (transmitterreceiver), they are placed at a given distance.In this research work, UPV test was performed on concrete with the inclusion of $0 \%, 5 \%, 10 \% 15 \%$, and $20 \%$ SBR polymer after 7 th, 14 th, and 28th days. Figure 6 displayed that the quality of concrete augmented with rise in quantity of SBR in concrete. The appearance of all mixes of concrete contains the excellent quality of concrete after 28th days. Concrete mix made 15\% and 20\% SBR dosage also show excellent quality after 14 days of curing age, while other mixes show good quality of concrete.

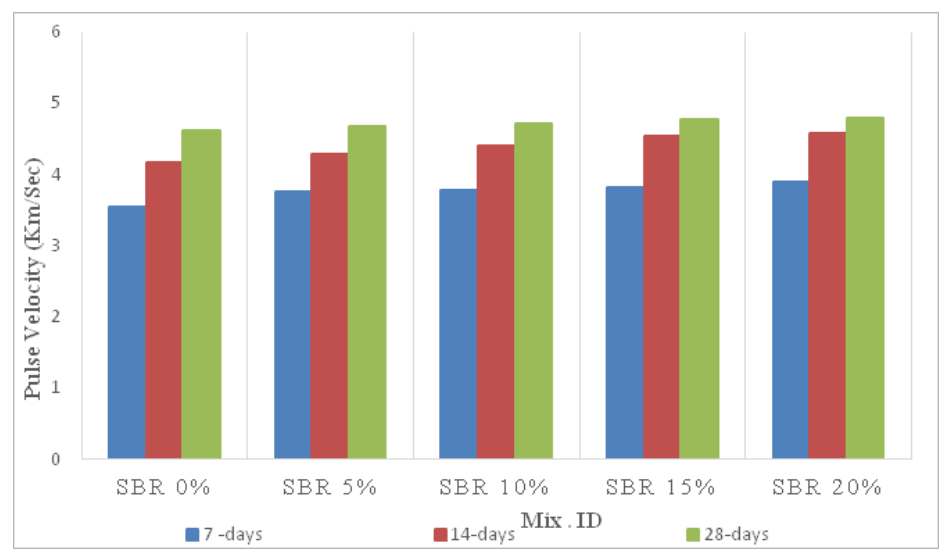

FIGURE 6. UPV test of all concrete mixes at different ages.

\subsection{Comparison Between Destructive and Non-Destructive Compressive Strength}

In this experimental work, the test results of destructive and non-destructive compressive strength were compared. It was notified that the destructive compressive strength was greater value as compared to non-destructive compressive strength as shown in Figure 7.

\section{Conclusion}

- The highest slump value was measured by $40 \mathrm{~mm}$ at $0 \%$ of SBR and the lowest slump value was recorded by $27 \mathrm{~mm}$ by using $20 \%$ of SBR as an admixture by the weight of cement in concrete, respectively. 


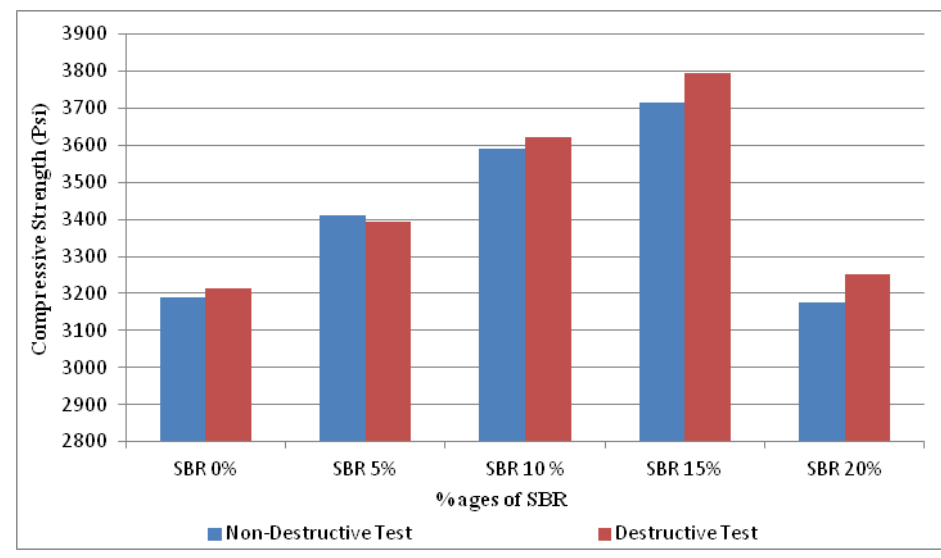

FIGURE 7. Comparison between destructive and non-destructive compressive strength @ 28 days.

- The maximum amount of compaction factor was measured by 0.86 at $0 \%$ of SBR polymer and the minimum amount of compaction factor was recorded by 0.75 blended with $20 \%$ SBR polymer by the weight of cement in concrete, respectively.

- The superior compressive strength was obtained by 3260 psi and 3715 psi with the addition of $15 \%$ SBR and the lowest compressive strength was measured by 2745 psi and 3175 psi blended with $20 \%$ of SBR in concrete after 14th and 28th days, respectively.

- The superior compressive strength was obtained by 2670 psi, 3240 psi, and 3795 psi with the addition of $15 \%$ SBR polymer and the lowest crushing strength was observed by 2145 psi, 2788 psi, and 3250 psi with the inclusion of $20 \%$ SBR polymer after 7 th, 14 th, and 28th days, respectively.

- The highest value of indirect tensile strength was measured by 618.91 psi, 742.86 psi, and 803.91 psi with the addition of $15 \%$ SBR and the lowest value of split tensile strength was recorded by $503.22 \mathrm{psi}, 670.93 \mathrm{psi}$, and $723.40 \mathrm{psi}$ with the inclusion of $20 \%$ SBR polymer in cement concrete after 7 th, 14 th, and 28 th days, respectively.

- The appearance of all mixes of concrete contains the excellent quality of concrete after 28 th days. Concrete mix made $15 \%$ and $20 \%$ SBR dosage also show excellent quality after 14 days of curing age, while other mixes show good quality of concrete.

\section{Acknowledgments}

Authors are thankful to Sarhad US\&IT Peshawar for providing required resources for carrying this research work.

\section{References}

1. Bheel ND, Meghwar SL, Abbasi SA, Marwari LC, Mugeri JA, Abbasi RA. Effect of rice husk ash and water-cement ratio on strength of concrete. Civil Engineering Journal. 2018; 4(10), 23732382. DOI: 10.28991/cej-03091166. 
2. Bheel N, Abro AW, Shar IA, Dayo AA, Shaikh S, Shaikh ZH. Use of rice husk ash as cementitious material in concrete. Engineering, Technology \& Applied Science Research. 2019; 9(3), 42094212. https://www.etasr.com/index.php/ETASR/article/view/2746

3. Bheel N, Meghwar SL, Sohu S, Khoso AR, Kumar A, Shaikh ZH. Experimental study on recycled concrete aggregates with rice husk ash as partial cement replacement. Civil Engineering Journal. 2018; 4(10), 2305-2314. https://civilejournal.org/index.php/cej/article/view/990

4. Mehta Pk. Durability of concrete--fifty years of progress? In: Durability of concrete. Second international conference. August 4-9, 1991, Montreal, Canada. . 1991; 1(1), 26-31. https://trid. trb.org/view/360987

5. Bheela ND, Memonb FA, Meghwar SL, Abroa AW, Shara IA. Millet husk ash as environmental friendly material in cement concrete. Proceedings of the 5th international conference on energy, environment and sustainable development, Mehran UET Jamshoro, Sindh, Pakistan. Energy and Environment Engineering Research Group. 2018, 153-158. https://www.researchgate.net/ publication/336639408_Use_of_Sugarcane_Bagasse_Ash_as_a_Fine_Aggregate_in_Cement_ Concrete

6. Bheel N, Abbasi RA, Sohu S, Abbasi SA, Abro AW, Shaikh ZH. Effect of tile powder used as a cementitious material on the mechanical properties of concrete. Engineering, Technology \& Applied Science Research. 2019; 9(5), 4596-4599. https://www.researchgate.net/ publication/336371750_Effect_of_Tile_Powder_Used_as_a_Cementitious_Material_on_the_ Mechanical_Properties_of_Concrete

7. Mindess S, Young JF, Darwin D. Concrete. Prentice-Hall: Englewood Cliffs, NJ. 1981; 481. https://trove.nla.gov.au/work/9840756?q\&versionId=45251401

8. Bheel ND, Abbasi SA, Meghwar SL, Shaikh FA. Effect of human hair as fibers in cement concrete. International Conference on Sustainable Development in Civil Engineering. 2017; 1, 67-72. http://ijesc.org/upload/96d3ad21de5c57d5c09457407ee3d8bc.Human\%20Hair\%20 as\%20Fibre\%20Reinforcement\%20in\%20Concrete.pdf

9. George J, Sreekala MS, Thomas S. A review on interface modification and characterization of natural fiber reinforced plastic composites. Polymer Engineering \& Science. 2001; 41(9), 14711485. https://doi.org/10.1002/pen.10846

10. Dayo AA, Kumar A, Raja A, Bheel N, Shaikh ZH. Use of sugarcane bagasse ash as a fine aggregate in cement concrete. Engineering Science and Technology International Research Journal. 2019; 3(3), 8-11. https://www.researchgate.net/publication/336639408_Use_of_Sugarcane_Bagasse_ Ash_as_a_Fine_Aggregate_in_Cement_Concrete

11. Wagner HB. Polymer-modified hydraulic cements. Industrial \& Engineering Chemistry Product Research and Development. 1965; 4(3), 191-196. https://doi.org/10.1021/i360015a011

12. Radhakrishnan R, SyamPrakash V, Thampan CK, Varma P. Performance of styrene butadiene rubber as a concrete repair material in tropical climate. International Journal of Advancements in Research \& Technology. 2012; 1(6), 118-122. https://www.researchgate. net/publication/258650206_Performance_of_Styrene_Butadiene_Rubber_as_a_Concrete_ Repair_Material_in_tropical_climate

13. Hwang EH, KoYS, Jeon JK. Effect of polymer cement modifiers on mechanical and physical properties of polymer-modified mortar using recycled artificial marble waste fine aggregate. Journal of Industrial and Engineering Chemistry. 2008; 14(2), 265-271. https://doi.org/10.1016/j. jiec.2007.11.002

14. Yao SY, Ge Y. Effect of styrene butadiene rubber latex on mortar and concrete properties. Advanced Engineering Forum. 2012; 5, 283-288. https://www.scientific.net/AEF.5.283 
15. Ohama Y. Principle of latex modification and some typical properties of latex-modified mortars and concretes adhesion; binders (materials); bond (paste to aggregate); carbonation; chlorides; curing; diffusion. Materials Journal. 1987; 84(6), 511-518. https://www.concrete.org/ publications/internationalconcreteabstractsportal $/ \mathrm{m} /$ details/id $/ 2463$

16. Baghini MS, Ismail A, Karim MR, Shokri F, Firoozi AA. Effect of styrene-butadiene copolymer latex on properties and durability of road base stabilized with Portland cement additive. Construction and Building Materials. 2014; 68, 740-749. https://doi.org/10.1016/j. conbuildmat.2014.06.061

17. Doğan M, Bideci A. Effect of styrene butadiene copolymer (SBR) admixture on high strength concrete. Construction and Building Materials. 2016; 112, 378-385. https://doi.org/10.1016/j. conbuildmat.2016.02.204

18. Soni K, Joshi, YP. Performance analysis of styrene butadiene rubber-latex on cement concrete mixes. Journal of Engineering Research and Applications. 2014, 3(1), 838-844. https://www.ijera. com/papers/Vol4_issue3/Version\%201/EM4301838844.pdf

19. Kim KK, Yeon J, Hee Lee J, Yeon KS. Feasibility study of SBR-modified cementitious mixtures for use as 3D additive construction materials. Polymers. 2019, 11(8), 1321. DOI: 10.3390/ polym11081321.

20. Kardon JB. Polymer-modified concrete. Journal of Materials in Civil Engineering. 1997; 9(2), 85-92.

21. Wang R, Li XG, Wang PM. Influence of polymer on cement hydration in SBR-modified cement pastes. Cement and Concrete Research. 2006; 36(9), 1744-1751. https://doi.org/10.1016/j. cemconres.2006.05.020

22. Karahan O, Atiş CD. Sugözü Uçucu Külünün Beton Katkısı Olarak Kullanılabilirliği. 7. Ulusal Beton Kongresi. 2007; 405-415. http://izmir.imo.org.tr/resimler/ekutuphane/pdf/3167.pdf

23. Rossignolo JA, Agnesini MV. Mechanical properties of polymer-modified lightweight aggregate concrete. Cement and Concrete Research. 2002; 32(3), 329-334. https://doi.org/10.1016/ S0008-8846(01)00678-0

24. Atiyah A, Saad BH Farid, SaadKadhim A. High performance concrete improvement by styrenebutadiene rubber Addition. Engineering and Technology Journal. 2016; 34(12), 2296-2309. https://www.iasj.net/iasj?func=article\&aId=120179

25. Qasim OA. Experimental investigation on effect of SBR and steel fiber on properties of different concrete types. International Journal of Civil Engineering and Technology. 2018; 9(2), 361-378. https://pdfs.semanticscholar.org/0136/cef83b69369edabad7d8ba47f8f582190bbb. pdf?_ga=2.115396934.1537187111.1578995962-161457859.1519384238

26. Yadav A, Thanvi SD. A Study on mechanical properties of polymer modified concrete used with plastic crush replacing natural sand. International Journal of Applied Engineering Research. 2019; 14(9), 12-15. https://www.ripublication.com/ijaerspl2019/ijaerv14n9spl_03.pdf

27. Shafieyzadeh M. Prediction of compressive strength of concretes containing silica fume and styrene-butadiene rubber (SBR) with a mathematical model. International Journal of Concrete Structures and Materials. 2013; 7(4), 295-301. https://link.springer.com/article/10.1007/ s40069-013-0055-y

28. Essa MS, Hassan NF. Effect of adding styrene butadiene rubber admixture (SBR) on concrete properties and bond between old and new concrete. Journal of Kerbala University. 2008; 6(2), 63-74. https://www.iasj.net/iasj?func=fulltext\&aId=49675 